\title{
Correction to: Pro Cryptography and Cryptanalysis with $\mathrm{C}++20$
}

\author{
M. I. Mihailescu \\ S.L. Nita
}

Correction to:

M. I. Mihailescu and S. L. Nita, Pro Cryptography and Cryptanalysis with $\mathrm{C}++20$ https://doi.org/10.1007/978-1-4842-6586-4

The inadvertently published contents have been corrected as mentioned below.

\section{Chapter 19}

In Page 389, the content "The solution for the source code is provided with due acknowledgment of the work of Jon King [10]." has been added next to the content "quite intuitive" in the paragraph starting with "Listing 19-1..."

In Page 390, the caption of Fig. 19-1 has been modified as "Differential Cryptanalysis Example [10]".

The updated online version of these chapters can be found at https://doi.org/10.1007/978-1-4842-6586-4_19

https://doi.org/10.1007/978-1-4842-6586-4_20 
In Page 390, the Listing 19-1 has a first line added up as "Credit to the work of Jon King [10]. In Page 400, the content “,with due acknowledgment of Jon King's work [11].” has been added next to the content "(see Figure 19-2)" in the paragraph starting with "This being said...."

In Page 400, the content "[11]" has been added at the end of the caption of Fig. 19-2.

In Page 409, the references "[10]. King Jon, Differential Cryptanalysis Tutorial. Available online: http://www. theamazingking.com/crypto-diff.php.

[11]. King Jon, Linear Cryptanalysis Tutorial. Available online: http://www. theamazingking.com/crypto-linear.php., has been added to the references list appearing at the end of the chapter page.

\section{Chapter 20}

In Page 413, the content "based on the work of Joan Daemon [1] and [2]" has been added next to the content "comments" in the paragraph starting with "In the source code....

In Page 414, the content "[1, 2]” has been added at the end of the caption of Listing. 20-1. In Page 422, the content "[1]" has been added at the end of the caption of Figure. 20-1. In Page 422, the current affiliation has been replaced with “[1] Joan Daemen, Lars Knudsen, and Vincent Rijmen(1997). The Block Cipher Square. Fast Software Encryption (FSE) 1997, Volume 1267 of Lecture Notes in Computer Science. Haifa, Israel; SpringerVerlag. pp. 149-165. CiteSeerX 10.1.1.55.6109.

[2] Paludan Github Repository. Integral Cryptanalysis Attack for AES. Available online: https://github.com/Paludan/AES/blob/master/AES/main.c. 